\title{
Irreducible Lateral Patellar Dislocation With Impaction Fracture of Patella and Large Femoral Osteophyte : A Case Report
}

\author{
Michael Bourgeois*, G Faivre, J Nallet, F Mille and L Obert \\ Department of Orthopedic Trauma, Plastic, Besançon University of Franche Comté, France
}

Submission: March 18, 2018; Published:April 02, 2018

*Corresponding author: Bourgeois M, Department of Orthopedic Trauma, Plastic, Reconstructive and Hand Surgery, CHRU Besançon - CHI Pontarlier \& CIC IT 808, Bd Fleming F25033 Besançon Université de Franche Comté, France, Email: mlmbourgeois@gmail.com

\begin{abstract}
Introduction: Irreducible lateral patellar dislocation is a rare phenomenon. Different mechanisms can explain irreducible patella disclocation: patellar vertical axis rotation, impaction fracture of the medial patellar facet, presence of lateral femoral osteophyte and patella with a concave medial facet.
\end{abstract}

Presentation of case: We report the third case of irreducible lateral patellar dislocation on a 86-year-old woman with a patellar impaction fracture of the medial facet trapped on a large lateral and anterior femoral osteophyte. Closed reduction was unsuccessful. CT scan and intraoperative assesement showed an impaction fracture of the medial patellar facet locked on a supporting femoral osteophyte. The anteral medial articular capsule was torn. After an open reduction, a medial patellofemoral ligament (MPFL) repair and a lateral patellofemoral ligament release, the patient had no further patellar dislocation again.

Discussion: Patella reduction can proove to be impossible because of several precise mechanisms : vertical axis rotation, impaction fracture of the medial patellar facet with or without lateral femoral osteophyte or patella with a concave medial facet. Theses mechanisms have to be identified by a Knee scan to avoid obstinated reduction which can provoke tendinous or osteochondral knee injuries. In these cases, we should be ready for an open reduction.

Conclusion: Irreducible lateral patellar dislocation is a rare condition. Several factors can explain such a condition. Knee scan is important to avoid going through tendinous or osteochondral knee injuries. Open reduction is advised.

Keywords: Irreducible; Lateral patellar dislocation; Impaction fracture; Femoral osteophyte ; Case report

\section{Introduction}

Patellar dislocation is a well known injury since Midelfart in 1887 [1]. Its incidence is about 6 to 7 per 100000 [2]. Patellar dislocation represents $3 \%$ of all traumatic knee injuries and two-thirds of cases concern young patient under 20 years of age [3]. Acute dislocation frequently occurs in young people after direct blow or twisting mechanism.

However, irreducible lateral patellar dislocation is a rare phenomenon. About $20 \%$ of patients may require a reduction for a persistently dislocated patella [2]. Spontanous reduction frequently occurs but sometimes external handlings are necessary. The knee is then extended and the pantela pushed medialy. The irreducible characteristic of this condition can come from a lateral patella dislocation with a medial impaction fracture against the lateral condyle [4]. This phenomenon needs to be identified to avoid tendinous and osteochondral injuries which may appear during obstinated patella reduction trials. We report the third case of post-traumatic irreducible lateral patellar dislocation with medial impaction fracture against the lateral condyle associated with a retentive femoral osteophyte. This case report is in line with the SCARE criteria [5].

\section{Case Report}

A 86-year-old woman was admitted to the Emergency unit after falling on ice while going to the hairdresser. She was complaining off her left knee after accidental torsion of her left lower limb. A past medical history included controlateral knee surgery for instability performed in 1944 without further detail, rigth-eye cararact, hypertension, bilateral total hip arthoplasty, radiculalgia due to herniated disc, hysterectomy and oophorectomy. The patient was painful with a Verbal Numerical Rating Scale (VNRS) of 7.

Physical left knee examination showed lateral patellar dislocation with bruises and hemarthrosis (Figure 1). The patient had a limited knee range of motion but full knee extension was 


\section{Orthopedics and Rheumatology Open Access Journal}

possible. Neurovascular examination was normal. Standard x-rays of the knee showed that the left patella was dislocated lateraly on a degenerative knee with an important anterior femoral osteophyte (Figure 2). A first attempt to reduce the patellar dislocation was performed using external maneuvers with extension and medial shift. This first reduction trial was attempted under entonox (nitrous oxide and oxygen), morphine and even under sedation using propofol.

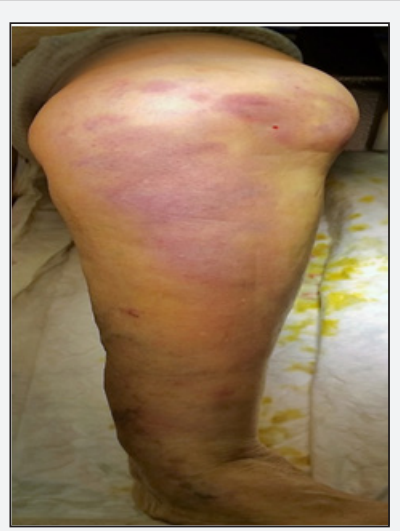

Figure 1: Photography showing the clinical examination of irreducible lateral patellar dislocation on the left knee.

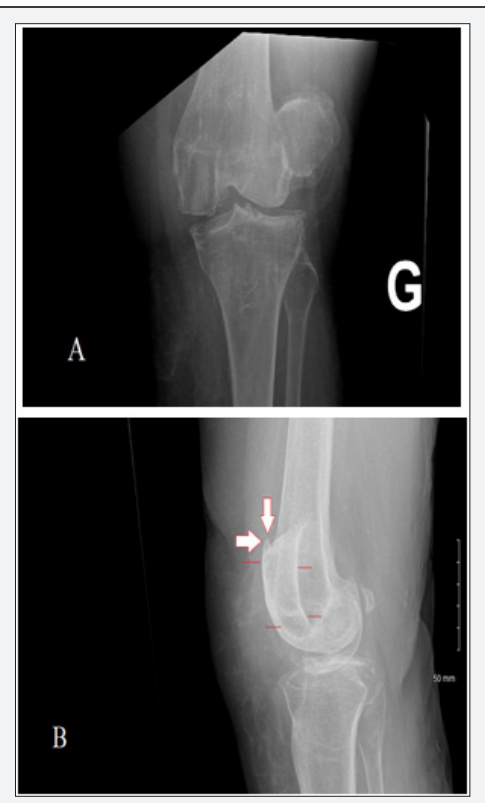

Figure 2 : Anterior-posterior (A) and lateral (B) X-Rays of 86-year-old woman showing dislocated patella locked on the femoral condyle on her left arthrosic knee. On lateral X-Rays (B), the arrows show an important lateral and anterior femoral osteophyte and the four red lines outline patella's position.

A second attempt to reduce the dislocation was performed under sterile conditions using bone forceps under general anesthesua and muscle relaxant. This second attempt was still unsuccesfull. A computed tomographie scan was performed because of irreducible state. The CT scan showed the lateral dislocation of the patella, an impaction fracture of the medial patellar facet and an important lateral and anterior femoral osteophyte hindering reduction (Figure 3). The Patient was taken to the operation theatre under general anesthesia and was prepared for surgery. A 10 centimeters long medial parapatellar incision was performed. A manual exploration revealed a longitudinal medial rupture of the articular capsule, a haematoma and a fracture of the medial patellar facet (Figure 4). The lateral femoral osteophyte was palpable.

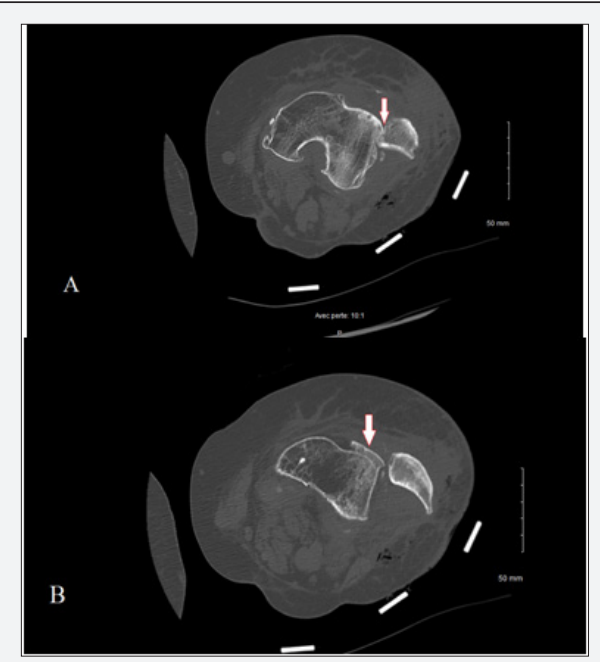

Figure 3 : Pré-operative Axial cuts of CT scan (A, B). The arrows show an impaction fracture of the medial patellar facet $(A)$ and an important lateral and anterior femoral osteophyte hindering reduction of the patella $(B)$.

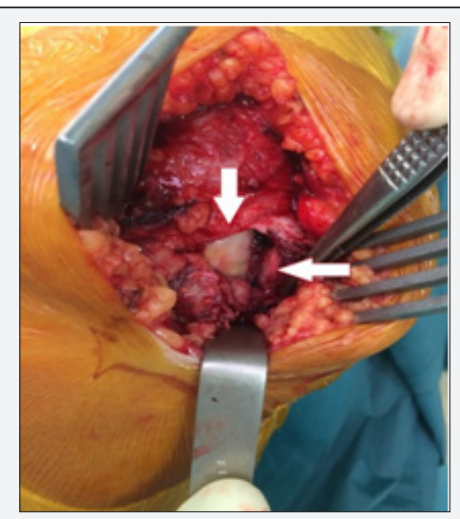

Figure 4: Intraoperative view of left knee. The anteral medial articular capsule was torn (vertical arrow). The horizontal arrow shows a part of the medial patella facet with sequelae of impaction.

The patella was reduced after medial fracture disimpaction. The joint capsule and the medial patellofemoral ligament (MPFL) were sutured while the lateral patellofemoral ligament was released. The lower limb was placed in a splint with full extension for a month together with a direct full weight bearin. The had a post operative radiographic assesement (Figure 5). Patellar instability's factors were: knee joint valgus of $5.8^{\circ}$. The TAGT was mesured at 12 millimeters. The Caton Deschamps index was mesured at 1,115 . There was no recurvatum, no patella alta and no trochlear dysplasia. After one month followup, the patella was still reduced. The knee flexion was about 


\section{Orthopedics and Rheumatology Open Access Journal}

60 degrees and extension was complete. Physical therapie was required to regain normal flexion.
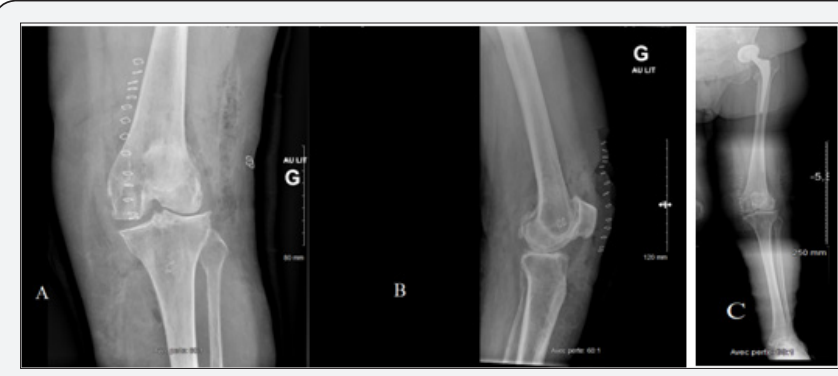

Figure 5 : Post operative radiographies. The anterior-posterior radiography show reducted patella, femorotibial osteoarthritis associated with a kneejoint valgus of $5,8^{\circ}(\mathrm{A}, \mathrm{C})$. The lateral radiography $(B)$ show reducted patella and an important anterior and lateral femoral osteophyte.

\section{Discussion}

Irreducible lateral patellar dislocation is a rare injury. Most of the time, lateral patellar dislocation is spontaneously reduced. Sometimes, the reduction is hindered due to precise mechanisms. Among those mechanisms, vertical axis rotation [6], impaction fracture of the medial patellar facet with [7] or without lateral femoral osteophyte [8], patella with a concave medial facet [9] are described in scientific literature (Figure 6). Other kinds of irreducible patellar are described such as intra articular dislocation [10] or superior dislocation [11]. Table 1 provides further information about published cases of Irreducible lateral patellar dislocation with fracture impaction of the medial patellar facet. Only two published articles before us report the association of fracture impaction of the medial patellar facet with the presence of a lateral supporting femoral osteophyte in a degenerative knee $[8,12]$.

Table 1: Published cases of irreducible lateral patellar dislocation with impaction fracture of medial patellar facet with ou without presence of supporting femoral osteophyte.

\begin{tabular}{|c|c|c|c|c|c|}
\hline Author (year) & Patient & Injury Mechanism & $\begin{array}{l}\text { Presence } \\
\text { of } \\
\text { Supporting } \\
\text { Femoral } \\
\text { Osteophyte }\end{array}$ & Associated Injury & Treatment \\
\hline Hackl [4] & $\begin{array}{c}\text { Woman, } 63 \text { years } \\
\text { old }\end{array}$ & $\begin{array}{l}\text { Fall from a chair, knee } \\
\text { torsion and direct } \\
\text { trauma. }\end{array}$ & No & $\begin{array}{l}\text { Bony avulsion of } \\
\text { the vastus medialis } \\
\text { muscle, the medial } \\
\text { retinaculumand the } \\
\text { medial crus of the } \\
\text { patellar tendon }\end{array}$ & $\begin{array}{l}\text { Medial cutaneous incision); } \\
\text { Hemarthrose washing and loose } \\
\text { bony fragment remooving; Medial } \\
\text { structures reattachement to the } \\
\text { medial patella with anchor and } \\
\text { suture; Lateral release. }\end{array}$ \\
\hline Phaltankar [13] & $\begin{array}{c}\text { Woman, } 66 \text { years } \\
\text { old }\end{array}$ & Knee torsion & No & $\begin{array}{l}\text { Medial patellar } \\
\text { retinaculum }\end{array}$ & Total knee replacement \\
\hline Feibel [10] & $\begin{array}{c}\text { Woman, } 66 \text { years } \\
\text { old }\end{array}$ & Mechanical fall on ice. & Yes & & $\begin{array}{l}\text { Medial cutaneous incision; Digital } \\
\text { disengagement of the patella from } \\
\text { the lateral femoral condyle }\end{array}$ \\
\hline Lowe [12] & $\begin{array}{c}\text { Man, } 50 \text { years } \\
\text { old }\end{array}$ & $\begin{array}{l}\text { Fall while he was } \\
\text { walking down hill }\end{array}$ & Yes & & $\begin{array}{l}\text { Medial para-patellar incision, } \\
\text { Reduction, Medial patellar } \\
\text { retinacular repair }\end{array}$ \\
\hline Yerimah [9] & $\begin{array}{c}\text { Man, } 21 \text { years } \\
\text { old }\end{array}$ & $\begin{array}{l}\text { Direct trauma; Blow } \\
\text { to the medial side of } \\
\text { his knee while he was } \\
\text { dancing in a pub. }\end{array}$ & No & $\begin{array}{l}\text { Osteochondral defect } \\
\text { on patella medial } \\
\text { border }\end{array}$ & $\begin{array}{c}\text { Medial cutaneous incision; Manual } \\
\text { patella reduction; Medial patellar } \\
\text { retinacular repair. }\end{array}$ \\
\hline $\begin{array}{c}\text { Delagrammaticas } \\
{[14]}\end{array}$ & $\begin{array}{c}\text { Woman, } 32 \text { years } \\
\text { old }\end{array}$ & $\begin{array}{l}\text { Knee torsion during } \\
\text { dance aerobics class. }\end{array}$ & No & $\begin{array}{l}\text { Avulsion fracture of } \\
\text { medal patellar border }\end{array}$ & $\begin{array}{l}\text { lateral parapatellar incision; } \\
\text { Manual patella reduction; Release } \\
\text { of the incarcerated lateral tissues. }\end{array}$ \\
\hline Grewal [3] & $\begin{array}{c}\text { Woman, } 32 \text { years } \\
\text { old }\end{array}$ & $\begin{array}{l}\text { Direct trauma, fall while } \\
\text { she was dancing in a } \\
\text { night club. }\end{array}$ & No & $\begin{array}{l}\text { Avulsion fracture of } \\
\text { medal patellar border }\end{array}$ & Closed reduction \\
\hline Bourgeois (2018) & $\begin{array}{c}\text { Woman, } 86 \text { years } \\
\text { old }\end{array}$ & $\begin{array}{l}\text { Direct trauma, fall on ice } \\
\text { while she was going to } \\
\text { the hairdresser. }\end{array}$ & Yes & & $\begin{array}{l}\text { Medial parapatellar incision, } \\
\text { reduction, Joint capsule and the } \\
\text { medial patellofemoral ligament } \\
\text { (MPFL) repair, Lateral release. }\end{array}$ \\
\hline
\end{tabular}




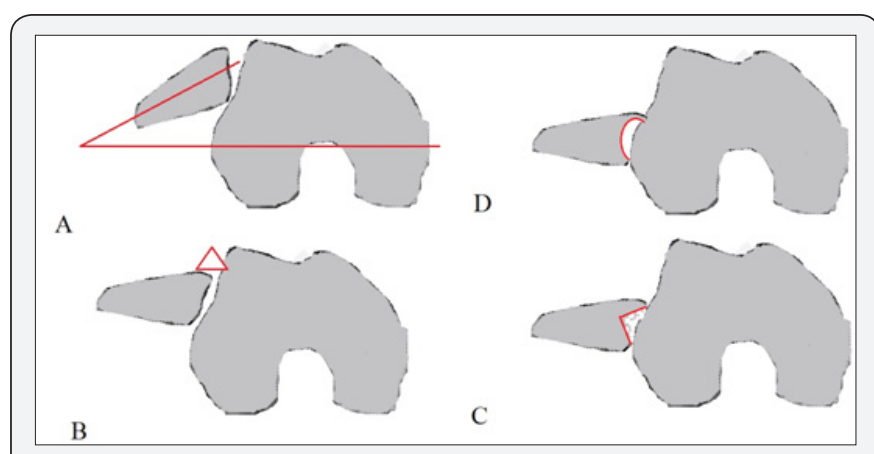

Figure 6 : Different mechanisms to explain how lateral patellar dislocation can be irreducible : (A) patella with a vertical axis rotation, (B) presence of supporting lateral and anterior femoral osteophyte in degenerative knee, (C) fracture impaction of the medial patellar facet $(D)$ patella with a concave medial facet conformation.

Medial patellar Impaction fracture can be compared to HillSachs lesion seen in the shoulder [7]. Reduction is impossible because of osteochondral fracture blocked on the femoral condyl. The presence of supporting osteophyte make the patella reduction even more difficult. Faced with this situation, we recommand a knee scan in order to identify the anatomical ground of the irreducible patellar. Indeed, obstinated reduction trials to reduce the patella can provoke tendinous or osteochondral knee injuries. Surgical treatement seems the most suitable one and must to be adapted to injuries identified on the scan as well as the injuries defined during surgery $[13,14]$.

\section{Conclusion}

Irreducible lateral patellar dislocation with impaction fracture of patella and a supporting anterior and lateral femoral osteophyte is a rare condition. This mecanism has to be indentified when the patellar reduction is impossible. A Scan seems mandatory and the treatment is often surgical.

\section{Conflict of Interest}

The authors declare no conflicts of Interest.

\section{Funding}

The authors declare no source of funding.

\section{Ethical Approval}

Ethical approval was not required for this study.

\section{Consent}

An oral and a written informed consent was obtained fromthe patient for publication of this case report and accompanying images.

\section{Author's contribution}

Michaël Bourgeois: Data collection, Writing the paper.

Jeremie Nallet: Data collection.

Grégoire Faivre: Data collection, Surgeon.

Fanny Mille: Data collection.

Laurent Obert: Supervisor.

\section{Guarantor}

The Guarantor is Michaël Bourgeois.

\section{References}

1. Midelfart (1887) En sjelden luxation of patella. Norsk Magazin for Laegevidenskaben 4: 588.

2. Duthon VB (2015) Acute traumatic patellar dislocation. Orthop Traumatol Surg Res OTSR. Févr 101(1): S59-S67.

3. Grewal B, Elliott D, Daniele L, Reidy J (2016) Irreducible Lateral Patellar Dislocation: A Case Report and Literature Review. Ochsner J 16(2): 180184

4. Hackl W, Benedetto KP, Fink C, Sailer R, Rieger M (1999) Locked lateral patellar dislocation: a rare case of irreducible patellar dislocation requiring open reduction. Knee Surg Sports Traumatol Arthrosc. 1 nov $7(6): 352355$.

5. Agha RA, Fowler AJ, Saeta A, Barai I, Rajmohan S, et al. (2016) The SCARE Statement: Consensus-based surgical case report guidelines. Int J Surg Lond Engl oct 34: 180186.

6. Higgins A, Khalfaoui MY (2016) Atraumatic Extra-articular Patellar Dislocation with Vertical Axis Rotation: A Case Study. J Orthop Case Rep mars 6(1): 5860.

7. Yerimah G, Eisenstein N, Turner R (2013) Irreducible lateral dislocation of patella. BMJ Case Reports.

8. Feibel RJ, Dehghan N, Cwinn AA (2007) Irreducible lateral patellar dislocation: the importance of impaction fracture recognition. J Emerg Med juill 33(1): 1115.

9. Louw P, Jansen van Rensburg NJ (2012) Irreducible or missed lateral patellar dislocation. SA Orthop J avr 11(2): 7275.

10. McHugh G, Ryan E, Cleary M, Kenny P, O’Flanagan S, et al. (2013) Intra-Articular Dislocation of the Patella. Case Reports in Orthopedics 535803: 3.

11. Hansen B, Beck C, Townsley R (2003) Arthroscopic removal of a loose body osteophyte fragment after superior patellar dislocation with locked osteophytes. Arthrosc J Arthrosc Relat Surg Off Publ Arthrosc Assoc N Am Int Arthrosc Assoc mars 19(3): E25.

12. Lowe M, Meta M, Tetsworth K (2012) Irreducible lateral dislocation of patella with rotation. J Surg Case Rep 1 mars 2012(3): 10.

13. Phaltankar PM, Bridle SH (2002) Locked lateral patellar dislocation with impaction fracture of patella. Ann R Coll Surg Engl. mars 84(2): 125126.

14. Delagrammaticas DE, Cordes SD (2016) A Rare Case of an Irreducible Patella Dislocation. Case Rep Med 2016: 3728425. 


\section{Your next submission with Juniper Publishers} will reach you the below assets

- Quality Editorial service

- Swift Peer Review

- Reprints availability

- E-prints Service

- Manuscript Podcast for convenient understanding

- Global attainment for your research

- Manuscript accessibility in different formats

( Pdf, E-pub, Full Text, Audio)

- Unceasing customer service

Track the below URL for one-step submission https://juniperpublishers.com/online-submission.php 